\title{
A Synthesis of i-READR Reading Intervention in the lives of Struggling Readers
}

Jose G. Tan, Jr., Michael B. Dodongan, Donna G. Magallanes, Jocelyn A. Matildo,

Grace O. Elipian, Mildin J. Retutas

Extension Head

College of Teacher Education and Technology

University of Southeastern Philippines

Apokon, Tagum City, Davao del Norte, Philippines

\begin{abstract}
Reading makes a difference in the lives of individuals. Studies show that it play a significant role in the students' educational performance. Evidence suggests that students who are proficient readers have a high tendency to be good academic performance in school. Reading skill open to wider perspective as it helps learners improve their communication and language skills. Propelled by this principle, the College of Teacher Education and Technology (CTET) of the University of Southeastern Philippines through an extension program, the Integrated Reading Enhancement Approach to Developing Readers ( $i$ - READR) manages to provide comprehensive and holistic approach in responding to the needs and social concerns that beset secondary students in their struggle for quality learning and meaningful education. CTET believes that the process of integrated and inclusive partnerships and actions among teachers, parents, and students might be of help to address this eminent problem. In order to have successful reading experiences, the significance of extensive and meaningful reading experiences was considered. This is the highlight of $i$ - READR through Summer Reading Remediation Camp conducted in the summer of three succeeding years from 2017 - 2019 in Sagayen National High School, Asuncion, Davao del Norte.
\end{abstract}

Keywords —Reading Camp, i-READR, Reading Remediation

\section{INTRODUCTION}

Classrooms across the nation speak of reality of life. Ideally, students are placed in well-ventilated classroom where learning is the main agendum. It presents an atmosphere which encourages order, participation, independence and continuous learning. Students show eagerness to learn as they express opinion, thought and excitement. But this scenario isn't always the case because reality shows that there are pressing concerns which need proper attention for appropriate actions. One of which is reading comprehension.

Reading has become a way of life. But in a more technical view, reading is a cognitive process which Cunningham \&Stanovich (1998) aptly expressed that a simple reading experience extend beyond what is written on a page. It has cognitive consequences which are reciprocal and exponential in nature. This process is associated with comprehension which makes it vital in the holistic development of learners (Tovani, 2000).

The problem of reading comprehension is attributed to many factors where some children are less exposed to printed materials at their early years. To intensify the problem, these children upon entering the school are faced with too many materials which are too much and too many for them (Allington, 1984). For example, a learner having deficient decoding skills, lacking practice and facing difficult materials poses a problem. At the end, this leads to lesser involvement in reading-related activities. Cain, Oakhill and Lemmon (2004) aptly expresses that learners who have poor reading comprehension face problem because they are impaired when demands of reading task are at hand. With this in mind, witnessing such a scenario as this where learning is at halt and affected because of the deficiency in reading of some students of Sagayen National High School (SNHS), Asuncion, Davao del Norte, an action is a must.

The i-READR as an extension program of the USeP - College of Teacher Education and Technology (CTET) responded to the call of time as it provides opportunities for collaboration of concerned stakeholders in the community in so far education is concerned.

Hence, this 3-year program intentionally targeted the readers classified as 'frustration-level' readers of SNHS. The Year 2 implementation serves as reinforcement of Year 1 implementation helping students who were still having difficulty in reading words, phrases, and sentences but recently have been able to enroll either in Grade 7,8 or 9. Likewise, teachers who handled them are also offered training and empowerment opportunities to functionally deal with students' reading problems and the proper use and integration of students' reading skills. 
Finally, parents who willingly entrust the education of their children to the teachers are also considered for a holistic support, reorientation ad participation.

\section{METHODOLGY}

Figure 1 shows the i-READR framework. The very core of the framework is the reader. The mechanism of the framework answers the objectives: combats illiteracy and innumeracy, capacitates mentors, promotes intergenerational lifelong learning; and strengthens partnership with stakeholders. This mechanism involves the concerted effort of stakeholders which is delegated by projects. These projects consisted of different activities which result to improved reading skills, strengthened partnerships and conceptualized research outputs.

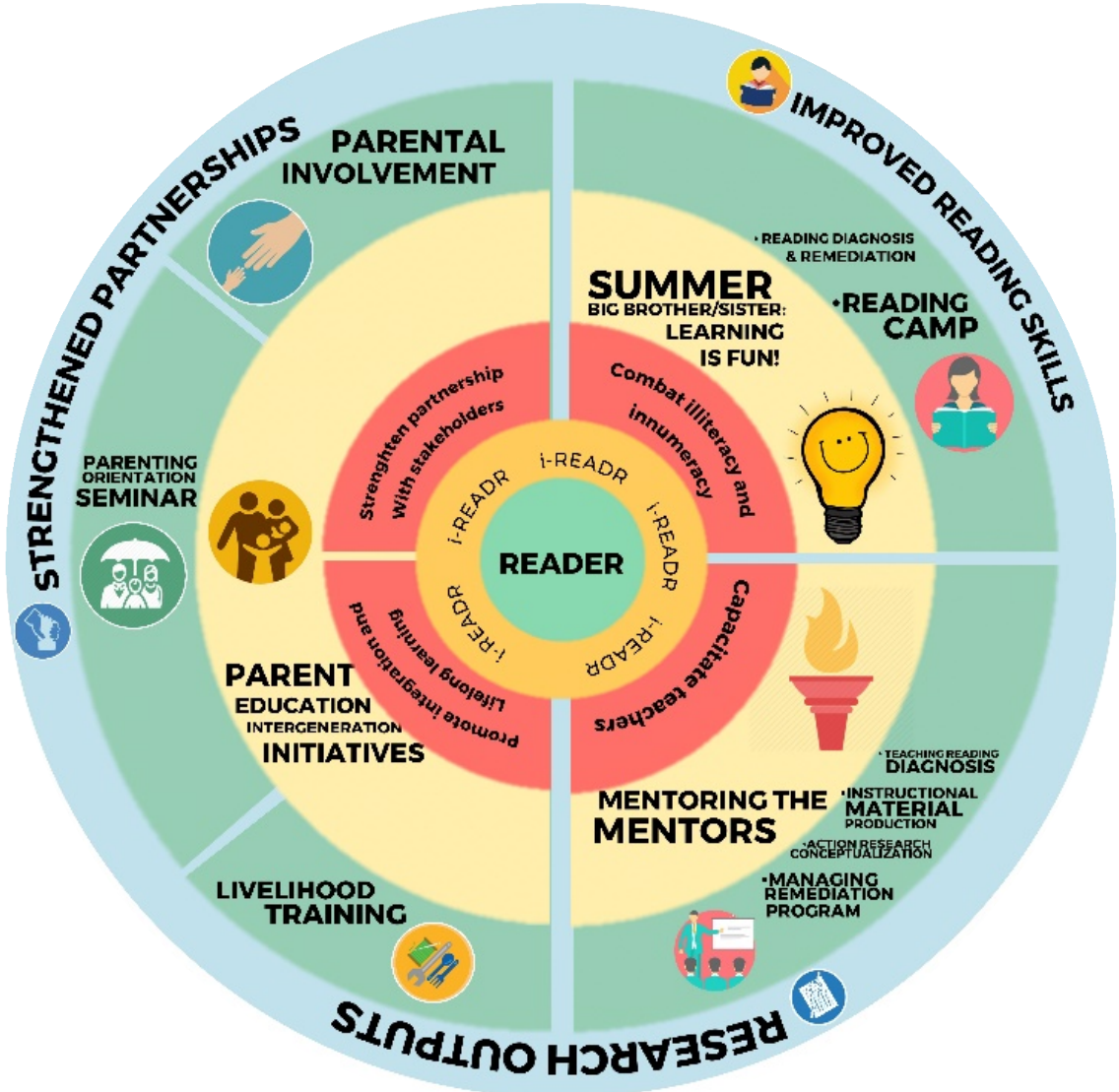

Figure 1. i - READR Framework

\section{A. Project 1: Community Organizing, Mobilization and Monitoring Evaluation}

The community as partner led to the successful conduct of different activities of the program. The community involvement in the 3 years of implementation from 2017 until 2019 was not that hard anymore because linkageswith the stakeholders were already established. But still, there were aspect which were considered like making of program design, project planning with target partners to obtain maximum community support designing of action plans and activities, time frame and budgetary requirements, fund sourcing/raising, stakeholders' campaign, meetings and information dissemination.

\section{B. Project 2: Mentoring the Mentors}

To equip teachers and volunteers, series of training and seminars were undertaken:

- Capability Training on using ART Tool in Reading Remediation

- Training on Action Research

- Training on Production of Instructional Materials for Reading Remediation 
These activities were conceptualized as prelude to the conduct of the Summer Reading Remediation Camp. Teacher volunteers were involved in the production of instructional materials, making of lesson designs as well as conceptualizing possible action researches. Experts were invited as resource speakers. Lesson designs and plans were made as outputs. These were properly critiqued by to come up with responsive learning materials.

This Project takes pride in transforming the non-reading teachers into teachers who are equipped with the basics of teaching reading and reading assessment and research. These are made possible through the previously cited activities.

\section{Project 3: Summer Big Brother/Sister: Learning is Fun}

The concept is based on the framework of the "Summer Big Brother/Sister (SBB) Reading is Fun" of the PLGU-Compostela Valley Province implemented under the 'Kalinga saKabataanBayanihan Para saKarunungan' (KK-BPSK) program in coordination with the Department of Education. The SBB serves as a reading remediation camp to improve the English reading skills targeting student - readers under 'frustration level' in Sagayen National High School.

There were three activities under Project 3. These include Diagnostics on Reading Skills of Students, Orientation - Seminar to Volunteer Teachers and Students, and Summer Reading Remediation Camp.

In order to set the stage ready for the conduct of the Reading Camp, the students were subjected to diagnostic testing (pretest). The diagnostics on the reading skills of the students was conducted to assess the performance of the current Grade 7 students of SNHS. Using the DepEd's Philippine Informal Reading Inventory (Phil-IRI), the pretest was focused on three reading skills, namely: word recognition, reading comprehension and reading speed. Those who were classified under "frustration" level in all three reading subskills were considered as beneficiaries of the Reading Camp. As a result, fifty (50) out of the one hundred sixty five (165) lowest performers were enrolled in the Camp. The same test was administered after the 15-day Reading Remediation Camp has been completed. Through this, the reading skills of those who were enrolled in the Camp were re-assessed.

The second activity is the Orientation-Seminar to the volunteer SNHS teachers and USeP BSEDEnglish PSTs. This group consists of the ones who were directly involved in the conduct of the remediation activities. In the said activity, the participants were introduced and were assigned to their shift which cover five (5) days. Both the teacher and PST groups were distributed to the three groups, namely: beginner, intermediate and advanced. The activity also included a presentation and orientation on the instructional materials that were developed for the specific groups, along with the schedules. These were to be used in the remediation activities. These materials were developed by the SNHS teachers themselves (in Project $2-$ Mentoring the Mentors). The highlight of the said event was the orientation on the tasks and responsibilities that were expected of each of them. Among the matters treated was the daily routines/activities in the Camp which would start at 6 o'clock in the morning and end at 9 o'clock in the evening.

The Reading Remediation Camp as the final activity of Project 3 envisions to help students of Sagayen National High School (SNHS) improve their reading skills. This year, there was a total of 73 campers, 21 teachers and 21 student-volunteers (see attached master list). The campers were categorized into groups as Beginning, Intermediate and Advanced. During the 3rd day of its implementation, the Beginning Group was further divided into Level 1, 2, 3 \& 4 where Level 1 had 15 campers; 15 for Level 2; 8 for Level 3; and 10 for Level 4. This was done based on the result of the further assessment, supported by observation. Everything at the camp involved storytelling, games, activities, group/small group dynamics and other hands-on and one-on-one activities. All of these were designed to maximize learning potentials and experience of the campers. The campers were given time to learn at their pace with constant supervision supported by instructional and reading materials. The days in the reading camp were structured to include (a) a general activity in the morning which is usually an exercise/zumba session to start up a day; (b) a reading segment which could be reading aloud, singing a song, silent reading, one-on-one instruction or peer tutoring; (c) an active game and group dynamics; (d) finishing up game; and reading log. All these were designed to address competencies in word recognition, reading comprehension and reading speed.

\section{Project 4: Parent Education: Inter-generational Initiatives}

An important element in the success of the implementation in the camp is the parents' participation. Before the reading camp, an orientation for the parents of the campers was scheduled in order for them to know their roles and responsibilities. Queries and questions were asked and answered during the orientation. To ensure that the parents would have the chance to see what their children were doing, they 
were grouped and assigned to perform tasks on a particular week. Like the camper, teachers, student volunteers and faculty overseer, they too have roles to play. They were tapped as volunteers to help and assist in the preparation of daily snacks and meals. Their work included providing firewood for the cooking and distribution of food. Various livelihood trainings as well were provided for them through the support of the barangay unit of Sagayen, Asuncion, Davao del Norte.

\section{DISCUSSIONS}

\section{A. i-Reader Partner Organizations/Agencies}

Partnership is a trend worldwide. This becomes a tool in addressing pressing issues and challenges. Partnership according to Otiso (2003) forges collaboration among groups, and organizations whose benefits exceed the costs of their participation. It's worth has been proven over the last decade (El Ansari, 2001). It was further said that there are realities and usefulness of partnership in addressing development.

i-READR's framework is built on the concept of partnership. The realization and sustainability of this program would not be possible without making the most of available resources by partnerships in the forms of manpower availability, financial, social, institutional, material, and educational supports. This is indeed true based on its 3 years of implementation. The Local Government Unit (LGU) of Asuncion together with the Barangay Council of Sagayen provided food, medical supplies and security personnel; the Department of Education (DepEd) provided the manpower through their teaching force of Sagayen National High School; the University of Southeastern Philippines (USeP) provided technical support as implementers; and parents provided moral support through their services during the Reading Remediation Camp.

All forms of resources and support initiatives from the partner institutions were be expected to boost the overall capability and capacity of host institution to plan and initiate ongoing and future projects and activities involved. Likewise, i-READR beneficiaries will be accommodated more comprehensively and in a wider context of continued privilege and participation. In this manner, all efforts and participation from partner institutions be expanded and may form as future basis for educational policy-making, community planning, and addressing stakeholders' needs in the suburbs.

B. i-READR Team Compositions and Counterparts from Partner Agencies

\begin{tabular}{|c|c|c|c|}
\hline Project & Title & $\begin{array}{c}\text { Program/Project } \\
\text { Leader }\end{array}$ & $\begin{array}{l}\text { Counterparts from the } \\
\text { Partner Institution }\end{array}$ \\
\hline 1 & $\begin{array}{l}\text { Community Organizing, } \\
\text { Mobilizing, and Monitoring } \\
\text { and Evaluation }\end{array}$ & Jose G. Tan, Jr. & $\begin{array}{c}\text { Marietta R. Ranis (2017 \& } \\
\text { 2018) } \\
\text { Evelyn P. Lucas (2019) } \\
\text { School Principals, SNHS } \\
\text { Eufracio P. Dayaday, } \\
\text { Municipal Mayor, Asuncion }\end{array}$ \\
\hline 2 & Mentoring the Mentors & $\begin{array}{c}\text { Michael B. Dodongan } \\
\text { (2017 \& 2018) } \\
\text { Mildin J. Retutas } \\
\text { (2019) }\end{array}$ & \multirow{3}{*}{$\begin{array}{l}\text { Ms. Rosannie P. Cornarco, } \\
\text { Reading Program in-charge, } \\
\text { SNHS }\end{array}$} \\
\hline 3 & $\begin{array}{c}\text { Summer Big Brother/Sister: } \\
\text { Learning is Fun }\end{array}$ & $\begin{array}{c}\text { Donna G. Magallanes } \\
\text { (2017 \& 2018) } \\
\text { Grace O. Elipian } \\
(2019)\end{array}$ & \\
\hline 4 & $\begin{array}{c}\text { Parent Education: } \\
\text { Intergenerational Initiatives }\end{array}$ & Jocelyn A. Matildo & \\
\hline
\end{tabular}

\section{Table 1. i - READR Team Management}

After the empowerment of the program management team of $\mathrm{i}-$ READR continuous and sustained planning and consultative meetings together with its stakeholders were done to finalize activities and prepare for various concerns. Among these were personnel in-charge and support staff functions including budget availability for the different activities. The management team also conducted a series of preliminary consultation with teachers for possible improvement in the conduct of projects and activities to have better result and deliverables. 


\section{Aggregate 3-Year Results}

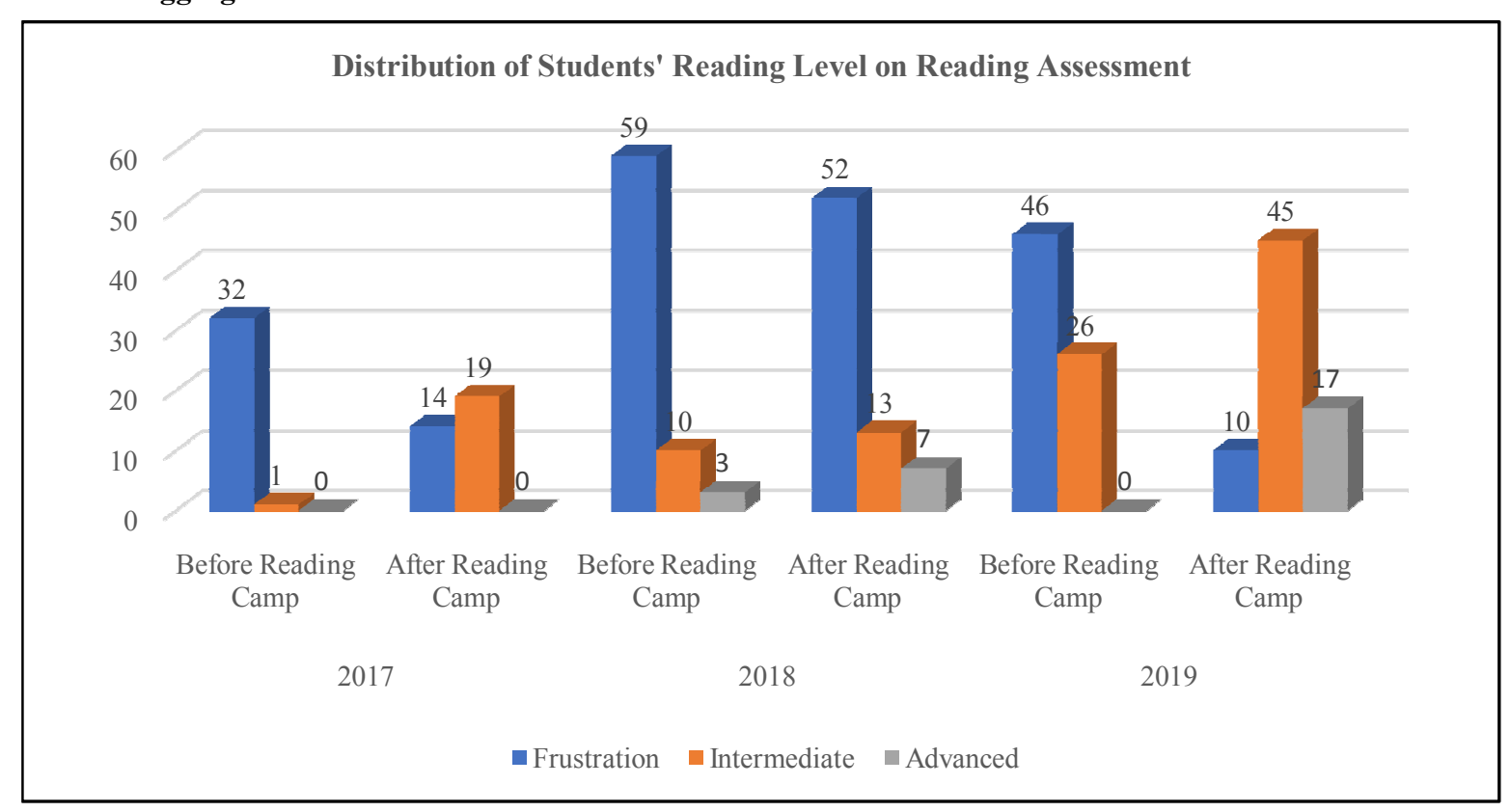

Figure 2. 3-Year Reading Assessment Results

Figure 2 shows the reading assessment results for 3 years starting from 2017 to 2019 through before and after readings. Respondents are categorized under frustration, intermediate and advanced level.

Data reveal thatout of 33 respondents before the reading camp, one is under intermediate and the rest is under frustration level. After reading camp, there are 14 respondents under frustration level intermediate levels, respectively. A number of respondents rise to intermediate level though almost half are still under frustration level. Year 2 (2018) result shows minimal changes of figure. From 59, 10 and 3 respondents under frustration, intermediate and advanced level, respectively before reading camp, these become 52, 13, and 3 after reading camp. Though the changes are minimal, changes are common in the 3 levels. Year 3 (2019) shows an astounding result. Before reading camp, there are 72 respondents where 46 is under frustration level, 26 under intermediate level and no respondents under advanced level. After the reading camp, there are only 10 respondents under frustration level, 45 respondents are under intermediate level and 17 of them rise to advanced level. This is therefore a significant change in the number of respondents going to another level.

Based on the data, there is an observable trend whereby after intervention of the reading camp a number of respondents improve in terms of their reading skills. This is supported by Reis, et al. (2011) who aptly expressed the significance of intervention especially to those having reading difficulties. This is the call of many educators and researchers to seek for solutions to answer the predicaments of reading difficulties (Swanson, et al., 2011).

\section{ISSUES AND CHALLENGES}

Mauricio Delgado, a mentor of Rutgers University once said that when people have uncontrollable setbacks, they need to cope with them in order to survive. The Program Management Team during the Year 2 implementation of i-READR faced setbacks which need to be addressed to have a better Year-3 implementation.

Preparation is the name of the game. The change of leadership of $i$ - READR was a minor setback which had an effect on the preparation of the projects and activities. The new program leaderand project leaders need to immerse in the program so well in order for them to be well-versed in terms of preparation and implementation in cognizant to what the program requires. This is important considering the bulk of work laid upon the faculty members involved in the program. The bulk of work is another setback which need to be addressed. The personnel involved in the program are full-time faculty members who have other functions and designations.

Moreover, another issue that showed up during the implementation is the commitment. Some of the partners fell short on this regard. The LGU of Asuncion through the support of the Hon. Mayor EufracioDayaday was supposed to provide 24/7 PNP personnel to ensure that the participants would be safe. Though there were PNP 
personnel who occasionally visit the site, the night shift was delegated to the barangay "tanod" who at many nights were not visible. But this issue was not much on the year 3 implementation.

Budget on the other hand became a major concern. The final implementation of the Reading Remediation Camp fell on the election ban. This means that the disbursement of funds from the mayor's office for the food wasn't allowed. It took us awhile to solve the problem. But thanks to the generosity of Dr. Evelyn P. Lucas, she provided means to disburse money with a promise to be reimbursed. The faculty members of CTET as well contributed funds since there was realty scarcity of financial resource. The Extension Division through Dr. Mervin G. Gascon provided additional fund.

\section{CONCLUSIONS AND RECOMMENDATIONS}

The Integrated Reading Enhancement Approach to Developing Readers (i-READR) Program with its projects which are headed by workaholic faculty members of the College of Teacher Education and Technology has proven to be of worth in the community. This is based on researches conducted. Feedback from teachers, parents and students supports this result. Evidence show that there was increased performance of word recognition and reading comprehension of the student-campers. Indeed, its implementation was a success. This was credited to all stakeholders who were involved in its implementation.

As the testimonies have shown, there have been remarkable changes in the lives of the participants, teachers and students alike. Most notable of all is the transformation that happened in the lives of our young readers. Teachers have noted that these students who used to stay quiet in class and make excuses to avoid involvement in reading-related activities have improved a lot. Not only have they started to get involved in reading, they have also developed an important improvement within themselves -self-confidence. Because of their interaction with their peers during the live-in fifteen-day Reading Camp, they have opened their doors to interacting with other students. They have developed trust in themselves that like reading that used to be a seemingly impossible task, they too could make friends. This was not among their activities before the Camp.

\section{ACKNOWLEDGMENT}

The management team of I - READR would like to express gratitude to the support extended by the University of Southeastern Philippines through the Extension Division. In same manner, our gratitude also is given to our partners who stood by our side. We would like to mention, Hon. Atty. EufracioDayaday, Dr. Josephine Fadul, Dr. Marietta Ranis, Dr. Evelyn Lucas, Dr. Jocelyn Matildo, Ms. RosannieConarco, teachers of Sagayeb National High School, faculty extensionists and student volunteers of the College of Teacher Education and Technology. To God be all the glory.

\section{REFERENCES}

[1] Allington, R. L. (1984). Content coverage and contextual reading in reading groups. Journal of Reading Behavior, 16, 85-96.

[2] Cain, K., Oakhill, J., \& Lemmon, K. (2004). Individual Differences in the Inference of Word Meanings From Context: The Influence of Reading Comprehension, Vocabulary Knowledge, and Memory Capacity. Journal of Educational Psychology, 96(4), 671-681.

[3] Cunningham, A.,\&Stanovich, K. (1998). What reading does for the mind. American Educator, V22, n1-2 p8-15 Spr-Sum. El Ansari, W., Phillips, C. J. \&Hammick, M. (2001) 'Collaboration and partnerships: developing the evidence base', Health and Social Care in the Community, (4), 9 pp. 215227.

[4] Otiso, K.M. (2003) "State, voluntary and private sector partnerships for slum upgrading and basic service delivery in Nairobi City, Kenya', Cities, Vol. 20, No. 4, p. 221-229.

[5] Reis, S. M., McCoach, D. B., Little, C. A., Muller, L. M., \&Kaniskan, R. B. (2011, April). The effects of differentiated instruction and enrichment pedagogy on reading achievement in five elementary schools. American Educational Research Journal, 48, 462-501. doi: $10.3102 / 0002831210382891$

[6] Swanson, E., Vaughn., S., Wanzek, J., Pestscher, Y., Heckert, J., Cavanaugh, C., ... \& Tackett, K.(2011, May/June). A synthesis of read-aloud interventions on early reading outcomes among preschool through third graders at risk for reading difficulties. Journal of Learning Disabilities, 44(3), 258-275. doi:10.1177/0022219410378444

[7] Tovani, C. (2000). I read it, but I don't get it: Comprehension strategies for adolescent readers. Portland, Me: Stenhouse Publishers 